\title{
El polo de desarrollo Lakia Tara en Tasba Raya y Sahsa
}

\section{Benigno Martínez}

Buenas tardes a todos y a todas, mi agradecimiento al Ing. Albert Sinclair por invitarme al evento. Me ha tocado hablar un poquito sobre los polos de desarrollo. Este término surgió mediante los acuerdos que firmó el gobierno de Nicaragua para el cese de fuego y para la desmovilización. A nosotros, los desmovilizados de YATAMA, en el año 1992, el gobierno de Nicaragua nos entregó un área boscosa en la región, específicamente, 15 mil manzanas que fueron entregadas en el municipio de Waspam, en el territorio de Tasba Raya, a 300 desmovilizados de YATAMA. Esa entrega está respaldada con un título de propiedad de la Reforma Agraria y nosotros conservamos esa tierra desde 1991 para acá. Antes del huracán, nosotros no aprovechamos mucho esa tierra, con el afán proveniente de nuestra cultura indígena de respetar y cuidar un poco el bosque.

Ahora, con el huracán, el bosque fue perjudicado en un 75\%. Lamentablemente, desde el huracán para acá, quizás, del 75\% del bosque tumbado por el huracán, si aprovechamos unos $500 \mathrm{~m}$ del bosque es mucho. Hace como un año, el INAFOR, la Comisión de Recursos Naturales del Consejo y el Gobierno Regional, impulsaron un programa de forestería comunitaria. Nosotros non integramos. Constituimos una empresa comunitaria de forestaría y también una cooperativa agrícola. El aprovechamiento forestal no fue muy efectivo, por dos razones sencillas, una de ellas es que en todo el verano no pudimos contactar empresas forestales que llegaran a la región a comprar esa madera. Es lamentable, pero algunos clientes internacionales llegaron hasta Managua y desde allí se regresaban. No pudieron entrar a la región. Perdimos, entonces, esas oportunidades y ahora en invierno la metodología de trabajo es completamente diferente. Esperamos que para el próximo verano tengamos recursos disponibles, pero consideramos que a través de los programas que tiene el gobierno central y el gobierno y el consejo regionales podamos, por lo menos, trabajar en la cuestión forestal.
Otro de los aspectos que quiero señalar es que, antes del huracán, con la ayuda de la universidad BICU-CIUM y POSAF habíamos elaborado 13 planes generales de manejo los cuales se cayeron con el huracán, y ahora la madera está caída y en mal estado.

En la actualidad tenemos grandes esperanzas en tres programas. Un primer programa es la forestaría comunitaria. Gracias a ese programa obtuvimos un aserrío, pudimos hacer un plan de aprovechamiento forestal y estamos, prácticamente amarrados a ese programa.

Otra esperanza que tenemos es un convenio con el gobierno regional, de garantizarle la madera que va a necesitar para la reconstrucción de las casas de las comunidades afectadas por el huracán en los litorales. No sé qué ha pasado con el Banco Mundial, que era el organismo que iba a financiar eso, pero va para dos años y sólo cuento: que llega, que llega y nada. No sabemos dónde está trabada la cosa, pues esos recursos fueron aprobados hasta por la Asamblea Nacional. Pero nosotros ya tenemos avanzado el acuerdo con el gobierno regional, de garantizar toda la madera que se va a necesitar para la reconstrucción de las casas de las comunidades. Pero todo eso depende ahora del Banco Mundial y de los trabones que puedan existir.

Otra esperanza que tenemos es a través de los programas del MAGFOR. En la actualidad, nosotros estamos instalando un banco de semillas en el Polo, donde vamos a meter toditas las variedades agrícolas y forestales, y de allí vamos a autoabastecernos, porque no es justo que nosotros sigamos dependiendo del Pacifico, pues todo lo que comemos viene de allí, y esto no puede seguir así, sobre todo teniendo nosotros tantos recursos, tanta área para trabajar. Entonces, pensando en eso estamos gestionando, a través de MAGFOR, instalar este banco de semillas en el Polo. Si Dios así dispone, quizás el otro año ya no vamos a tener que traer semilla del Pacifico para sembrarla aquí. 